\title{
Knockdown of BAMBI inhibits $\beta$-catenin and transforming growth factor $\beta$ to suppress metastasis of gastric cancer cells
}

\author{
KAI LIU ${ }^{1,2}$, XILIN SONG ${ }^{2}$, HENG MA ${ }^{2}$, LIQING LIU ${ }^{2}$, XIAOWEN WEN ${ }^{2}$, \\ JIANYONG YU ${ }^{2}$, LONGGANG WANG ${ }^{2}$ and SANYUAN HU ${ }^{1}$ \\ ${ }^{1}$ Department of General Surgery, Qilu Hospital of Shandong University, Jinan, Shandong 250012; \\ ${ }^{2}$ Department of Gastrointestinal Surgery, Shandong Tumor Hospital, Jinan, Shandong 250117, P.R. China
}

Received July 30, 2013; Accepted May 29, 2014

DOI: $10.3892 / \mathrm{mmr} .2014 .2305$

\begin{abstract}
The upregulation of bone morphogenetic protein and activin membrane-bound inhibitor (BAMBI) has been observed in several types of malignant cancer, including thyroid, ovarian, liver and colorectal cancer. However, the pathological role and the regulatory mechanism of BAMBI in gastric cancer remain to be elucidated. The present study revealed that the expression of BAMBI was upregulated in gastric cancer tissue, and was correlated with tumor metastasis, disease recurrence and low survival rates in patients. Knockdown of BAMBI in aggressive gastric cancer cell lines significantly inhibited their malignant behavior, including in vitro invasion and cell proliferation. $\beta$-catenin expression was downregulated as a result of knocking down of BAMBI, and TGF- $\beta$ was downregulated in a similar manner. These results demonstrated the association between BAMBI expression and gastric cancer progression, and indicate a promising direction for developing novel strategies to improve the prognosis and therapy of gastric cancer.
\end{abstract}

\section{Introduction}

Bone morphogenetic protein and activin membrane-bound inhibitor (BAMBI) has been confirmed as a transmembrane glycoprotein and is a member of the transforming growth factor- $\beta$ (TGF- $\beta$ ) family $(1,2)$. BAMBI is an extracellular signal transducer (3). Yan et al (4) also demonstrated that BAMBI was able to interact with $\mathrm{Smad} 7$ to regulate the signaling of TGF- $\beta$ family proteins. Fritzmann et al (5) reported that $\mathrm{BAMBI}$ was highly expressed in metastatic primary colorectal cancer tumors when compared with that in nonmetastatic colorectal cancer tumors. It was suggested that

Correspondence to: Dr Sanyuan Hu, Department of General Surgery, Qilu Hospital of Shandong University, 107 Wenhua Xi Road, Jinan, Shandong 250012, P.R. China

E-mail: husanyuan1962@hotmail.com

Key words: bone morphogenetic protein and activin membrane-bound inhibitor, $\beta$-catenin, N87, gastric cancer
BAMBI regulates colorectal cancer metastasis via interaction with the Wnt $/ \beta$-catenin and TGF- $\beta$ pathways. In addition, BAMBI affects angiogenesis and endothelial cell homeostasis by modulating TGF- $\beta$ expression (6). BAMBI has also been shown to protect the murine heart by inhibiting the TGF- $\beta$ pathway (7). The overall function of BAMBI is the regulation of a variety of biological activities in organisms through interaction with the TGF- $\beta$ pathway.

TGF- $\beta$ is crucial in apoptosis, the cell cycle and the immune system $(8,9)$. Downregulation of TGF- $\beta$ expression has been reported to result in tumor suppression (10). TGF- $\beta$ signaling is upregulated by stimulation of secreted ligand, which promotes tumorigenesis and increases metastasis (11). Thus, understanding the function of the TGF- $\beta$ signaling pathway is vital for determining the malignant phenotype. To date, the TGF- $\beta$ signaling pathway has been considered as a tumor-suppressor pathway that inhibits carcinogenic progression (11).

BAMBI has been shown to promote cell survival via Wnt/ $\beta$-catenin signaling (12). Another study showed that 5-aminoimidazole-4-carboxamide-1-beta-4-ribofuranoside mediated death of hepatic stellate cells, which downregulated TGF- $\beta$ and increased BAMBI expression (13). The study suggested that metformin increased BAMBI expression and activated Wnt/ $\beta$-catenin in hepatic stellate cells. This study also indicated that BAMBI was positively correlated with the Wnt/ $\beta$-catenin expression. Wnt/ $\beta$-catenin mediates a number of developmental processes in organisms. The main focus of $\mathrm{Wnt} / \beta$-catenin research is on the mechanism underlying its involvement in tumorigenesis. Decreased expression of Wnt/ $\beta$-catenin promotes tumorigenesis and angiogenesis in tumor tissues (14). In particular, $\beta$-catenin stabilization by Wnt has been shown to be mediated by proteins of the T-cell factor (TCF)/lymphoid-enhancer binding factor (LEF) family, which are able to induce bending of the DNA helix and expression of T-cell specific genes $(15,16)$. These effects inhibit tumorigenesis, which indicates that $\beta$-catenin may be a key drug target. With the connection between BAMBI and the Wnt/ $\beta$-catenin pathway being established, the confirmation of its universality in different types of tumor may contribute to further elucidating the mechanism and thus developing novel treatment strategies.

The aforementioned data allow for the hypothesis that deregulated expression of BAMBI may be involved in gastric 
Table I. Primer sequences.

\begin{tabular}{lll}
\hline Primer name & Direction & Sequence $\left(5^{\prime}\right.$ to $\left.3^{\prime}\right)$ \\
\hline BAMBI & Forward & CTAGAGAAGCAGGCGCTGAG \\
$\beta$-Catenin & Reverse & ATCGCCACTCCAGCTACATC \\
& Forward & GCTGATTTGATGGAGTTGGAC \\
TGF- $\beta$ & Reverse & AGGAGCTGTGGTAGTGGCACCAGAATGGAT \\
$\beta$-actin & Forward & GTACACTACGGCGGAGGATTG \\
& Reverse & CGCTTCGATTCGCTTTCTCT \\
& Forward & CTCTCTTCCAGCCTTCCTTC \\
\hline
\end{tabular}

BAMBI, bone morphogenetic protein and activin membrane-bound inhibitor; TGF, transforming growth factor.

cancer development. Using transfection analysis, the present study aimed to determine the knockdown effect of BAMBI on gastric cancer cells and the underlying molecular mechanism. The purpose of the present study was to investigate the potential therapeutic application of the knockdown of BAMBI in gastric cancer.

\section{Materials and methods}

Antibodies. Rabbit antibodies against human BAMBI (HPA010866), $\beta$-catenin (C2206), TGF- $\beta$ (SAB4502954) and $\beta$-actin (AV40173) were purchased from Sigma (St. Louis, MO, USA). The secondary antibodies conjugated to horseradish peroxidase against rabbit IgG (sc-2030) were purchased from Santa Cruz Biotechnology, Inc. (Santa Cruz, CA, USA).

Clinical specimens, cells, plasmids and transfection. Clinical samples were removed from 10 patients during tissue excision surgery at the Qilu Hospital of Shandong University (Jinan, China) and 60 patients were recruited for the 24-month survival analysis. Informed patient consent and approval from the institutional review board of the Qilu Hospital of Shandong University were obtained. The samples were paired and samples from 10 patients were subjected to semi-quantitative polymerase chain reaction (qPCR) and immunohistochemistry. The N87 human gastric adenocarcinoma cell line was obtained from the American Type Culture Collection (Manassas, VA, USA).

For comparison of biophysical properties following knockdown and overexpression of BAMBI, BAMBI interference and overexpression vectors were constructed. The recombinant expression plasmid of BAMBI small hairpin RNA (shRNA) was purchased from Santa Cruz Biotechnology, Inc. (sc-62576-SH). The recombinant expression plasmid of BAMBI was constructed. Briefly, the open reading frame of BAMBI (GenBank accession, NM012342) was cloned into the plasmid pcDNA3.1(t) (Invitrogen Life Technologies, Inc., Carlsbad, CA, USA) between the XhoI and BamHI sites to build the recombinant plasmid pcDNA3.1(t) BAMBI. The cells were transfected with pcDNA3.1(t)-BAMBI and/or

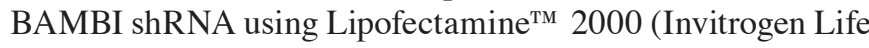
Technologies) according to the manufacturer's instructions. Following transfection and incubation for $24 \mathrm{~h}$, the cells were harvested and used for the experiments described below.
Table I. Correlation between BAMBI expression and clinicopathological factors in 60 patients with gastric cancer.

\begin{tabular}{|c|c|c|c|}
\hline \multirow[b]{2}{*}{ Characteristic } & \multicolumn{2}{|c|}{ BAMBI expression } & \multirow[b]{2}{*}{ P-value } \\
\hline & Low $(1,2)$ & $\operatorname{High}(3,4)$ & \\
\hline Age & & & 0.64 \\
\hline Years $($ mean $\pm \mathrm{SD})$ & $59.23 \pm 7.80$ & $55.42 \pm 10.30$ & \\
\hline Gender & & & 0.45 \\
\hline Male & 12 & 11 & \\
\hline Female & 13 & 14 & \\
\hline Tumor stage & & & 0.01 \\
\hline $\mathrm{I}+\mathrm{II}$ & 15 & 7 & \\
\hline III + IV & 5 & 23 & \\
\hline Tumor status & & & 0.02 \\
\hline $\mathrm{T} 1-\mathrm{T} 2$ & 12 & 15 & \\
\hline T3-T4 & 13 & 10 & \\
\hline Lymph node metastasis & & & 0.02 \\
\hline No & 15 & 5 & \\
\hline N1-N3 & 9 & 21 & \\
\hline Distal metastasis status & & & 0.03 \\
\hline M0 & 20 & 7 & \\
\hline M1 & 9 & 14 & \\
\hline Recurrence status & & & 0.00 \\
\hline Recurrence & 5 & 21 & \\
\hline No recurrence & 21 & 3 & \\
\hline
\end{tabular}

BAMBI, bone morphogenetic protein and activin membrane-bound inhibitor; SD, standard deviation.

The cells were randomly divided into three groups (five parallel treatments for each group), including control (non-treated group), BAMBI interference group (transfected with $1 \mu \mathrm{g}$ BAMBI shRNA) and BAMBI overexpression group (transfected with $1 \mu \mathrm{g}$ pcDNA3.1(t)-BAMBI).

$q P C R$. Total RNA was extracted with TRIzol ${ }^{\circledR}$ (Invitrogen Life Technologies) according to the manufacturer's instructions. 
A

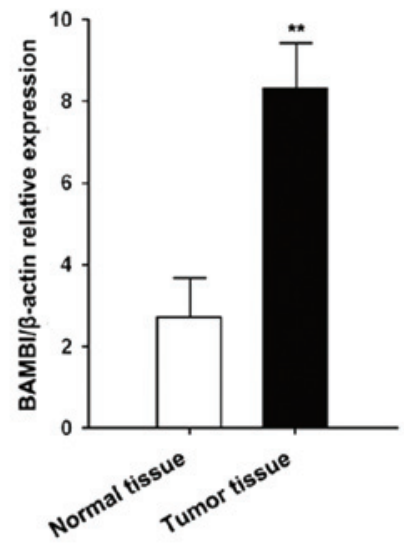

B

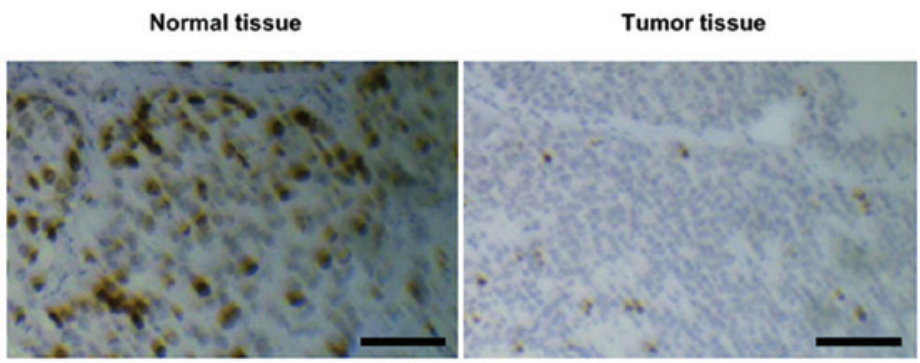

C

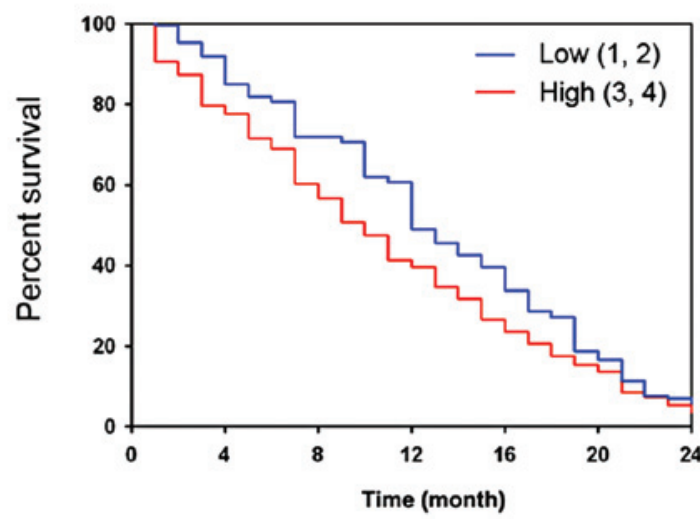

Disease-free survival

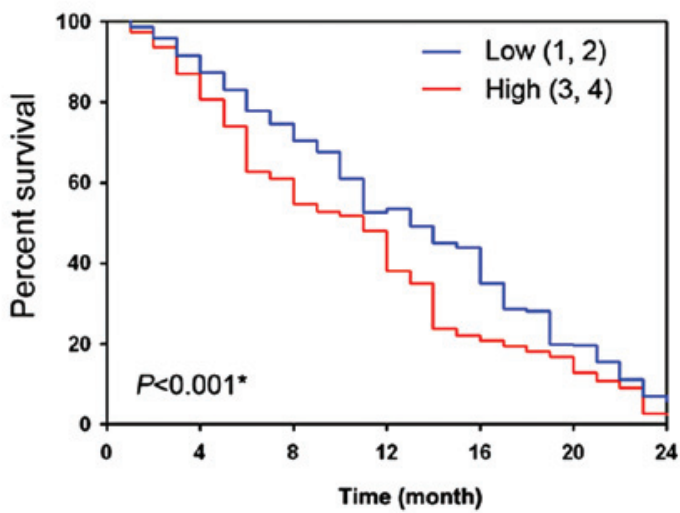

Figure 1. BAMBI expression in gastric cancer tissues and its correlation with survival rates. (A) Transcript levels of BAMBI mRNA expression in normal and tumor tissue. (B) Immunohistochemistry of BAMBI in normal and gastric cancer tissue. Scale bar, $100 \mu \mathrm{m}$. (C) Overall and disease-free survival rates in patients with low (relative expression between 1 and 2) and high (relative expression between 3 and 4) expression levels of BAMBI. BAMBI, Bone morphogenetic protein and activin membrane-bound inhibitor; shBAMBI, small hairpin BAMBI.

First-strand cDNA was reverse transcribed using SuperScript II reverse transcriptase (Life Technologies, Gaithersburg, MD, USA) from $1 \mu \mathrm{g}$ RNA. The primers were designed by GenBank (National Institute for Biotechnology Information, Bethesda, MD, USA) (Table I). An aliquot of $20 \mathrm{ng}$ cDNA was used for the $50 \mathrm{ml}$ qPCR reaction. The PCR reaction was performed using the Applied Biosystems 7500 Real-Time PCR system (Life Technologies). The protocol was as follows: One cycle of $94^{\circ} \mathrm{C}$ for $4 \mathrm{~min}, 40$ cycles of $94^{\circ} \mathrm{C}$ for $30 \mathrm{sec}, 60^{\circ} \mathrm{C}$ for $30 \mathrm{sec}$ and $72^{\circ} \mathrm{C}$ for $30 \mathrm{sec}$. The PCR products were assayed by dissociation curve to verify single product generation at the end of the assay. Following the PCR reaction, the relative expression levels were calculated using the SDS 1.3 software (Life Technologies) on the Applied Biosystems 7500 Real-Time PCR system.

Immunohistochemistry. Paraffin tissue sections were prepared and dewaxed. Then the sections were blocked in $4 \%$ evaporated milk for $30 \mathrm{~min}$. Following incubation with the primary and second antibodies for $24 \mathrm{~h}$ and $30 \mathrm{~min}$, respectively, the signals were stained by horseradish peroxidase (HRP) catalyzed TMB chromogenic staining. For cell immunohistochemistry, the cells were first cultured on the sterile glass cover slips and then fixed in $4 \%$ paraformaldehyde solution for $30 \mathrm{~min}$. Subsequently, the cells were blocked in $4 \%$ evaporated milk for $30 \mathrm{~min}$. Following incubation with the primay antibodies for $24 \mathrm{~h}$ at $4^{\circ} \mathrm{C}$ and fluorescein isothiocyanate-conjugated secondary antibody (Santa Cruz Biotechnology, Inc.) for $30 \mathrm{~min}$. Incubation for 5 min with fluorescent dye 4'-6-diamidino-2-phenylindole was used to stain the nucleus. Then the signals were visualized by a fluorescence microscope (Axiover 200M; Carl Zeiss, Oberkochen, Germany).

Western blot analysis. Cells were lysed in radio-immunoprecipitation assay (Life Technologies) buffer on ice following centrifugation at 25,200 $\mathrm{x}$ g for $15 \mathrm{~min}$ to obtain the supernatant. The extracted protein samples were separated by $12 \%$ SDS-PAGE and transferred onto polyvinylidene fluoride membranes (Amersham Pharmacia Biotech, Picastaway, NJ, USA). The membranes were blocked in 5\% skimmed milk for $30 \mathrm{~min}$ and subsequently incubated with primary antibodies overnight at $4^{\circ} \mathrm{C}$. Following washing with phosphate-buffered saline (PBS) three times, the samples were incubated with secondary antibodies conjugated to horseradish peroxidase for $1 \mathrm{~h}$ at room temperature and washed with PBS three times. The membranes were then incubated with the secondary antibody. The blots were evaluated using the chemiluminescence system SuperSignal West Pico Chemiluminescent Substrate (Pierce Biotechnology, Inc., Rockford, IL, USA). Experiments were performed as three independent repeats to assess the relative protein levels. 
A

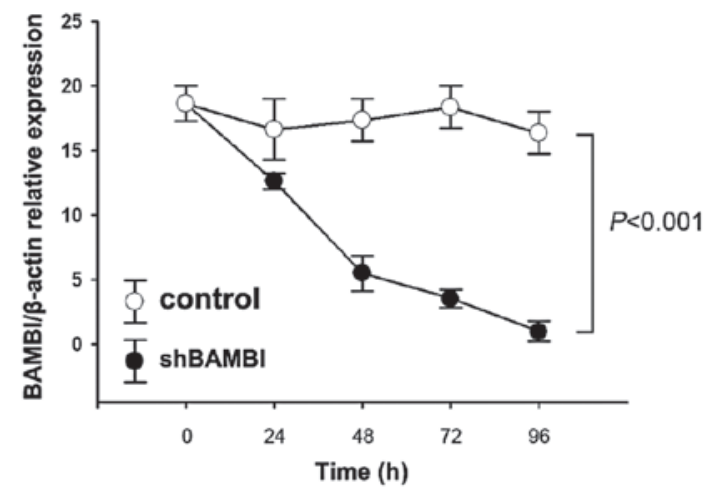

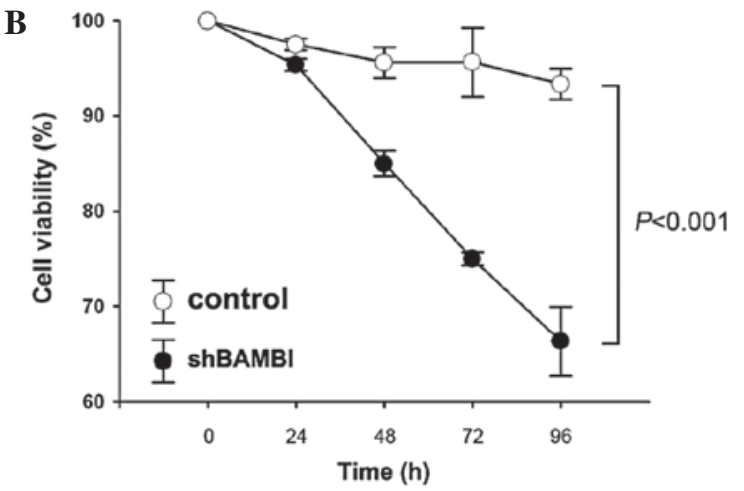

D

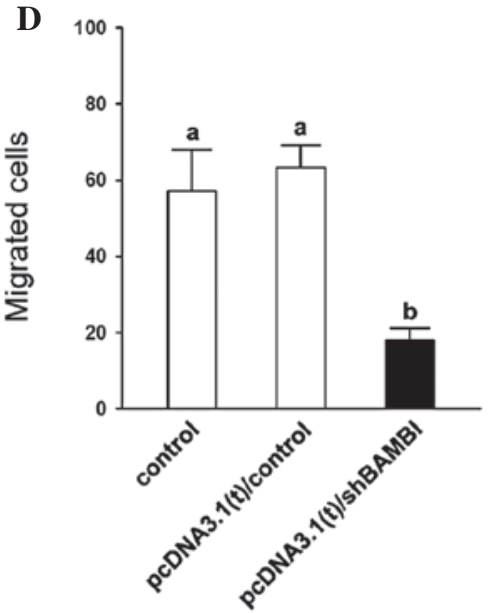

Figure 2. Cell biological activites following shBAMBI vector transfection. (A) BAMBI mRNA levels at different time-points following shBAMBI vector transfection. (B) Cell viability at different time-points following shBAMBI vector transfection. (C,D) Invaded and migrated cells following shBAMBI vector transfection for control, pcDNA 3.1(t)/control and pcDNA 3.1(t)/shBAMBI groups. ${ }^{\mathrm{a}, \mathrm{b}}$ Different letters indicate significant differences among the groups $(\mathrm{P}<0.05)$. BAMBI, Bone morphogenetic protein and activin membrane-bound inhibitor; shBAMBI, small hairpin BAMBI.

Cell invasion assay. Cell invasion assays were performed in 24-well FluoroBlok cell culture inserts (BD Biosciences, San Jose, CA, USA) with an $8-\mu \mathrm{m}$-pore size polyethylene terephthalate membrane (BD Biosciences). The insert was coated with $200 \mu \mathrm{l}$ Matrigel matrix (1 $\mu \mathrm{g} / \mu \mathrm{l}$, BD Biosciences) and incubated at $4^{\circ} \mathrm{C}$ overnight. Following starvation for $6 \mathrm{~h}$ in serum-free Dulbecco's modified Eagle's medium (DMEM; Life Technologies), cells were harvested from one subconfluent $10-\mathrm{cm}$ dish by incubation with cell dissociation buffer (Life Technologies), centrifuged at $448 \mathrm{x}$ g for $5 \mathrm{~min}$ and resuspended in DMEM. The cells $\left(1 \times 10^{5}\right.$ in $500 \mu$ l DMEM) were seeded onto the insert and $250 \mu \mathrm{l}$ DMEM with $10 \%$ FBS was added into the lower chamber of the transwells. Following incubation for $18 \mathrm{~h}$ at $37^{\circ} \mathrm{C}$, the medium inside the insert was removed and the insert was placed in a fresh 24 -well plate. The invaded cells at the reverse side of the insert were labeled with the fluorescent dye Calcein AM (4 $\mu \mathrm{M}$ in PBS; BD Biosciences) for $1 \mathrm{~h}$ at $37^{\circ} \mathrm{C}$. Fluorescence was detected at $494 \mathrm{~nm} / 517 \mathrm{~nm}$ (excitation/emission wavelength) using a Beckman DU-800 (Beckman Coulter, Inc., Carlsbad, CA, USA) ultraviolet spectrophotometer.

Statistical analysis. All data are presented as the mean \pm standard error of the mean of independent experiments. One-way analysis of variance was used to determine differences among groups. The normality and constant variance for experimental data were analyzed by Levene's test. Data that did not have homogenous variance underwent logarithmic transformation to meet the requirements of analysis of variance. $\mathrm{P} \leq 0.05$ was considered to indicate a statistically significant difference. If $\mathrm{P}$-values exceeded the critical value $(\mathrm{P}<0.05)$, the Newman-Keul's post hoc test was performed to compare the groups. The statistical analyses were performed each month. Kaplan-Meier curves were assembled in Prism version 6 (GraphPad software, San Diego, CA, USA). Mean survival times were estimated from the Kaplan-Meier curves. Comparisons between survival curves were made using the log-rank test.

\section{Results}

Increased expression of BAMBI in gastric cancer. To the best of our knowledge, the present study was the first to assess the expression of BAMBI in gastric cancer. The expression levels of BAMBI mRNA in tumor lesions of patients with gastric cancer were assessed using qPCR. Out of 50 tumor samples, 47 had a higher expression level of BAMBI than the respective adjacent normal tissue (Fig. 1A). In addition, the results showed that the upregulated expression levels of BAMBI were correlated with distal metastasis and recurrence of disease (Table 2). The expression of BAMBI protein was upregulated in gastric tumor tissue rather than normal 
A

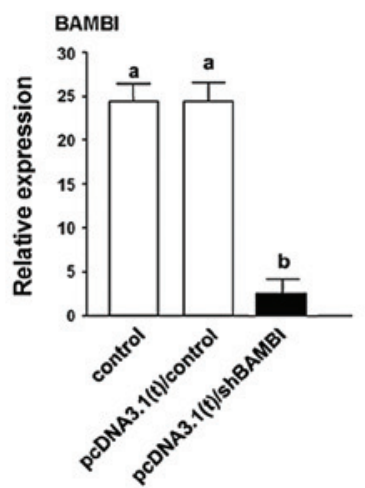

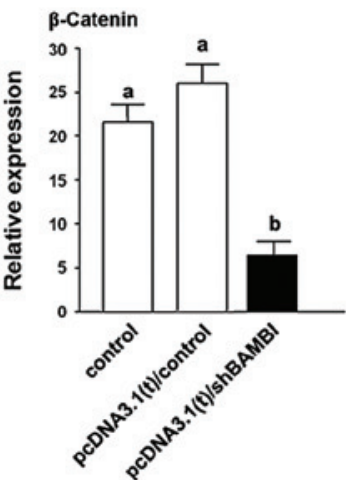

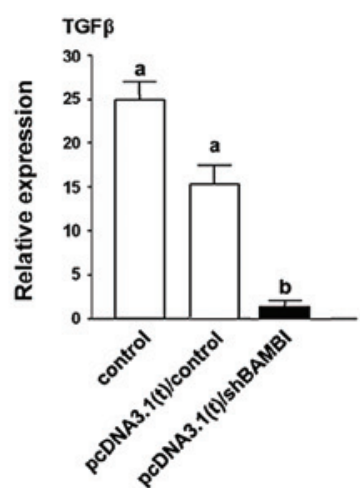

B

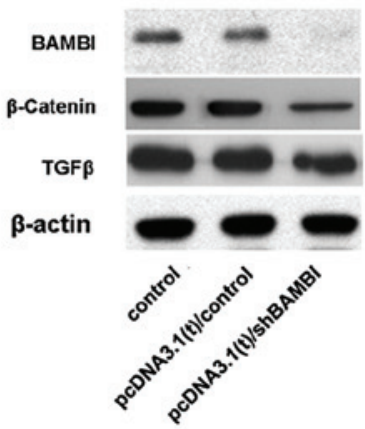

C

BAMBI

$\beta$-Catenin

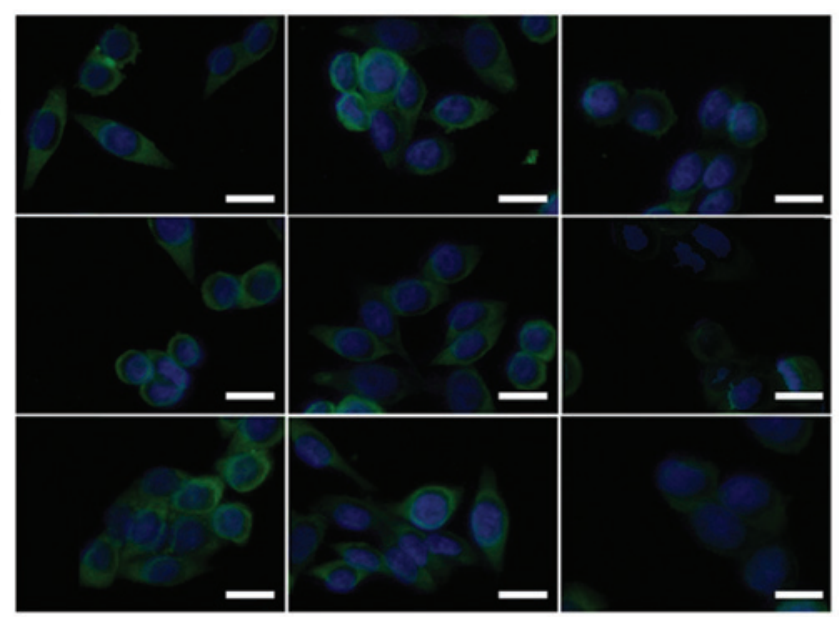

TGF $\beta$
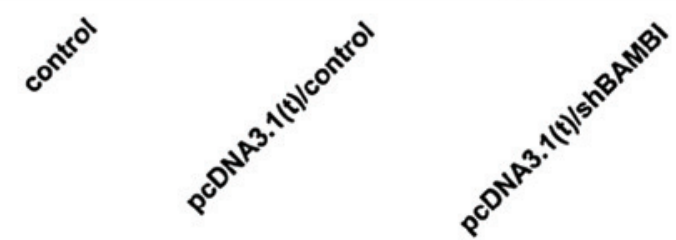

Figure 3. Correlation of $\beta$-catenin and TGF- $\beta$ expression in N87 cells. (A) mRNA expression levels among control,pcDNA 3.1(t)/control and pcDNA 3.1(t)/shBAMBI groups; protein expression levels assayed by (B) western blot analysis and (C) immunofluorescence. Fluorescein isothiocyanate is shown in green and indicates protein expression. DAPI staining shown in blue indicated the nucleus. ${ }^{\mathrm{a}, \mathrm{b}}$ Different letters indicate significant differences among the groups $(\mathrm{P}<0.05)$. BAMBI, Bone morphogenetic protein and activin membrane-bound inhibitor; shBAMBI, small hairpin BAMBI, TGF, transforming growth factor.

tissue (Fig. 1B). Kaplan-Meier survival curves (Fig. 1C) showed that BAMBI expression was associated with overall and disease-free survival. Individuals with low expression levels of BAMBI mRNA (relative expression of 1-2) showed a significantly higher overall survival and disease-free survival rate than individuals with high expression levels of BAMBI mRNA (relative expression of 3-4).

Knockdown of BAMBI leads to decreased cell migration in a gastric cell line. To investigate the effect of BAMBI knockdown on human gastric cells, N87 cells were transfected with the BAMBI interference vector, and the resulting characteristics were assessed. Following transfection with shBAMBI, the expression of BAMBI decreased significantly (Fig. 2A). In addition, a time-dependent effect was revealed following transfection, with mRNA expression levels reaching a minimum $96 \mathrm{~h}$ post transfection.

Knockdown of BAMBI also had a negative effect on the cell growth and invasion ability of N87 cells (Fig. 2B-D).
Similarly, the effect on cell viability was observed to be time dependent. The lowest cell viability was found $96 \mathrm{~h}$ post transfection. Thus, $96 \mathrm{~h}$ of incubation following transfection were the optimal conditions in the present study. Subsequently, the invasion and migration abilities were calculated and showed a significant decrease $96 \mathrm{~h}$ post transfection with the BAMBI interference vector $(\mathrm{P}<0.05)$.

Increase of Wnt $/ \beta$-catenin and TGF- $\beta$ by BAMBI. The mechanism underlying the BAMBI expression in gastric cancer and decreased cell migration following BAMBI knockdown was investigated. The effects of shBAMBI transfection on tumor migration factors, including $\beta$-catenin and TGF- $\beta$, were confirmed. Under the optimal treatment conditions, $96 \mathrm{~h}$ posttransfection, the transcription of $\beta$-catenin and TGF- $\beta$ expression levels were significantly decreased $(\mathrm{P}<0.05$; Fig. 3A). Western blot analysis and immunofluorescence also suggested a decreased expression of $\beta$-catenin and TGF- $\beta$ following knockdown of BAMBI (Fig. 3B and C). 


\section{Discussion}

The present study revealed that BAMBI was abnormally expressed in gastric cancer tissue and that an increase in BAMBI expression was associated with an increased recurrence and lower survival rates. BAMBI protein is highly homologous to TGF- $\beta$ /BMP type-I receptors $(17,18)$, the only difference is that BAMBI lacks an intracellular serine/threonine kinase domain. Thus, the pseudoreceptor BAMBI can bind to the TGF $\beta / \mathrm{BMP} /$ activin receptor and antagonize TGF $\beta / \mathrm{BMP}$ and activin signaling. BAMBI is involved in carcinogenesis and tumor progression via this mechanism. Consistent with the present study, a number of studies have shown that BAMBI regulates TGF- $\beta$ /BMP signaling in colorectal, hepatocellular and gastric carcinoma $(4,19,20)$. Furthermore, in bladder cancer, BAMBI gene expression is epigenetically altered during cancer progression, which contributes to the promotion of cell motility, invasion and survival via TGF- $\beta$ /BMP signaling (21). In addition, the suppression of the BAMBI gene by promoter hypermethylation affects the invasiveness and aggressiveness of bladder cancer. In accordance with these studies, the present study also showed that BAMBI expression was significantly increased in gastric cancer tissue as compared with normal gastric tissue. Furthermore, the present study assessed the effects of the knockdown of BAMBI on gastric cancer cells by transfection.

Following transfection, the suppression of BAMBI expression significantly inhibited tumor metastasis in the N87 gastric cancer cell line. Notably, knockdown of BAMBI affected cell growth and the ability to metastasize. In addition, the invasion ability of N87 cells was significantly decreased following knockdown of BAMBI. Despite studies demonstrating that a decrease in BAMBI expression increases the metastatic potential of ovarian and colorectal cancer $(2,5)$, the same has not been demonstrated in gastric cancer thus far. Fritzmann et al (5) showed that activation of BAMBI expression in colorectal cancer requires B-cell lymphoma protein (BCL-2) as well as $\beta$-catenin. The study suggested that BCL- 2 is necessary but not sufficient to coactivate BAMBI expression in metastatic tumors as it is not a metastasis marker. Thus, this mechanism requires to be further elucidated.

It has been reported that TGF- $\beta$ signaling participates in early tumor suppression as well as in late tumor progression $(22,23)$. The present study suggested that TGF- $\beta$ signaling is regulated by BAMBI in gastric cancer cells (3). Previous studies have demonstrated that TGF- $\beta$ signaling promotes migration and metastasis, induces epithelial-mesenchymal transition and enhances metastasis in gastric cancer cells (24). This indicates that TGF- $\beta$ induced growth and apoptosis at early stages of tumor development. In addition, TGF- $\beta$ inhibits epithelial-mesenchymal transition and metastasis at late stages of tumor development. In addition to the TGF- $\beta$ pathway, $\beta$-catenin was regulated by BAMBI in the present study. $\beta$-catenin has a dual function in epithelial cells, which is depended on the localization of $\beta$-catenin expression (25). At the plasma membrane, $\beta$-catenin, which is associated with E-cadherin and $\alpha$-catenin, has an important role in adherens junctions (26). However, in the nucleus, $\beta$-catenin acts as an effector of the Wnt signaling cascade (27). $\beta$-catenin present in the cytoplasm is quickly taken up into the nucleus, unless the Wnt signaling cascade is activated. In the present study, BAMBI knockdown was able to downregu- late $\beta$-catenin expression, which alleviated the aggressiveness of gastric cancer cells. Higher BAMBI levels may contribute to the upregulation of $\beta$-catenin and induce epithelial-mesenchymal transition and metastasis.

In conclusion, the present study indicated that the overexpression of BAMBI in gastric cancer tissue may be a cause of the pathology. Loss of BAMBI inhibited of tumor metastasis in the N87 gastric cancer cell line. The present study suggested that knockdown of BAMBI contributed to the negative regulation of $\beta$-catenin and TGF- $\beta$ in N87 cells, which may be a potential therapy for human gastric cancer.

\section{References}

1. Guillot N, Kollins D, Gilbert V, et al: BAMBI regulates angiogenesis and endothelial homeostasis through modulation of alternative TGF $\beta$ signaling. PLoS ONE 7: e39406, 2012.

2. Pils D, Wittinger M, Petz M, et al: BAMBI is overexpressed in ovarian cancer and co-translocates with Smads into the nucleus upon TGF- $\beta$ treatment. Gynecol Oncol 117: 189-197, 2010.

3. Onichtchouk D, Chen YG, Dosch R, et al: Silencing of TGF- $\beta$ signalling by the pseudoreceptor BAMBI. Nature 401: 480-485, 1999.

4. Yan X, Lin Z, Chen F, et al: Human BAMBI cooperates with Smad7 to inhibit transforming growth factor- $\beta$ signaling. J Biol Chem 284: 30097-30104, 2009.

5. Fritzmann J, Morkel M, Besser D, et al: A colorectal cancer expression profile that includes transforming growth factor $\beta$ inhibitor BAMBI predicts metastatic potential. Gastroenterology 137: 165-175, 2009.

6 . De Caestecker M: The transforming growth factor- $\beta$ superfamily of receptors. Cytokine Growth Factor Rev 15: 1-11, 2004.

7. Villar AV, García R, Llano M, et al: BAMBI (BMP and activin membrane-bound inhibitor) protects the murine heart from pressure-overload biomechanical stress by restraining TGF- $\beta$ signaling. Biochim Biophys Acta 1832: 323-335, 2013.

8. Yang L, Pang Y and Moses HL: TGF- $\beta$ and immune cells: an important regulatory axis in the tumor microenvironment and progression. Trends Immunol 31: 220-227, 2010.

9. Schiffer M, Bitzer M, Roberts IS, et al: Apoptosis in podocytes induced by TGF- $\beta$ and Smad7. J Clin Invest 108: 807-816, 2001.

10. Markowitz SD and Roberts AB: Tumor suppressor activity of the TGF- $\beta$ pathway in human cancers. Cytokine Growth Factor Rev 7: 93-102, 1996.

11. Derynck R, Akhurst RJ and Balmain A: TGF- $\beta$ signaling in tumor suppression and cancer progression. Nat Genet 29: $117-129,2001$.

12. Lin Z, Gao $\mathrm{C}$, Ning $\mathrm{Y}, \mathrm{He} \mathrm{X}, \mathrm{Wu} \mathrm{W}$ and $\mathrm{Chen} \mathrm{YG}$ : The pseudoreceptor BMP and activin membrane-bound inhibitor positively modulates Wnt/ $\beta$-catenin signaling. J Biol Chem 283: 33053-33058, 2008.

13. Subramaniam N, Sherman MH, Rao R, et al: Metformin-mediated Bambi expression in hepatic stellate cells induces prosurvival Wnt $/ \beta$-catenin signaling. Cancer Prev Res (Phila) 5: 553-561, 2012 .

14. Clevers H: Wnt $/ \beta$-catenin signaling in development and disease. Cell 127: 469-480, 2006.

15. Daniels DL and Weis WI: $\beta$-Catenin directly displaces Groucho/TLE repressors from Tcf/Lef in Wnt-mediated transcription activation. Nat Struct Mol Biol 12: 364-371, 2005.

16. Jho E-h,Zhang T, Domon C, Joo C-K, Freund JN and Costantini F: Wnt $/ \beta$-catenin/Tcf signaling induces the transcription of Axin2, a negative regulator of the signaling pathway. Mol Cell Biol 22: $1172-1183,2002$

17. Miyazono K, Kusanagi K and Inoue H: Divergence and convergence of TGF $\beta /$ BMP signaling. J Cell Physiol 187: 265-276, 2001.

18. Miyazono K, Maeda S and Imamura T: BMP receptor signaling: transcriptional targets, regulation of signals, and signaling cross-talk. Cytokine Growth Factor Rev 16: 251-263, 2005.

19. Miyazono K: Positive and negative regulation of TGF- $\beta$ signaling. J Cell Sci 113: 1101-1109, 2000.

20. Sekiya T, Oda T, Matsuura K and Akiyama T: Transcriptional regulation of the TGF- $\beta$ pseudoreceptor BAMBI by TGF- $\beta$ signaling. Biochem Biophys Res Commun 320: 680-684, 2004. 
21. Khin SS, Kitazawa R, Win N, et al: BAMBI gene is epigenetically silenced in subset of high-grade bladder cancer. Intl J Cancer 125: 328-338, 2009.

22. Wakefield LM and Roberts AB: TGF- $\beta$ signaling: positive and negative effects on tumorigenesis. Curr Opin Genet Dev 12: 22-29, 2002

23. Akhurst RJ and Derynck R: TGF- $\beta$ signaling in cancer - a double-edged sword. Trends Cell Biol 11: S44-S51, 2001.

24. Thiery JP: Epithelial-mesenchymal transitions in tumour progression. Nat Rev Cancer 2: 442-454, 2002.
25. Brembeck FH, Rosário M and Birchmeier W: Balancing cell adhesion and Wnt signaling, the key role of $\beta$-catenin. Curr Opin Genet Dev 16: 51-59, 2006.

26. Drees F, Pokutta S, Yamada S, Nelson WJ and Weis WI: $\alpha$-catenin is a molecular switch that binds E-cadherin- $\beta$-catenin and regulates actin-filament assembly. Cell 123: 903-915, 2005.

27. Veeman MT, Axelrod JD and Moon RT: A second canon: functions and mechanisms of $\beta$-catenin-independent Wnt signaling. Dev Cell 5: 367-377, 2003. 